\title{
1 Spatial and functional structure of an entire ant assemblage in a lowland Panamanian
}

2 rainforest

4 Maurice Leponce ${ }^{\mathrm{a}, \mathrm{b},{ }^{*}, \text { Bruno Corbara }^{\mathrm{c}} \text {, Jacques H. C. Delabie }}{ }^{\mathrm{d}, \mathrm{e}}$, Jérôme Orivel ${ }^{\mathrm{f}}$, Henri-Pierre

5 Aberlenc $^{\mathrm{g}}$, Johannes Bail ${ }^{\mathrm{h}}$, Hector Barrios ${ }^{\mathrm{i}}$, Ricardo I. Campos ${ }^{\mathrm{j}}$, Ivan Cardoso do Nascimento ${ }^{\mathrm{k}}$, Arthur

6 Compin $^{1}$, Raphaël K. Didham ${ }^{\mathrm{m}, \mathrm{n}}$, Andreas Floren ${ }^{\mathrm{o}}$, Enrique Medianero ${ }^{\mathrm{i}}$, Sérvio P. Ribeiro ${ }^{\mathrm{p}}$, Yves

7 Roisin $^{\mathrm{b}}$, Juergen Schmidl ${ }^{\mathrm{q}}$, Alexey K. Tishechkin ${ }^{\mathrm{r}}$, Neville N. Winchester ${ }^{\mathrm{s}}$, Yves Basset ${ }^{\mathrm{i}, \mathrm{tu}}$, Alain

8 Dejean $^{\mathrm{f}, 1}$

9

$10{ }^{a}$ Royal Belgian Institute of Natural Sciences, Operational Directorate Natural Environment, 1000

$11 \quad$ Brussels, Belgium.

$12{ }^{b}$ Université Libre de Bruxelles, Evolutionary Biology and Ecology, 1050 Brussels, Belgium.

$13{ }^{c}$ Université Clermont-Auvergne, CNRS, LMGE, Clermont-Ferrand, France.

$14{ }^{d}$ Laboratório de Mirmecologia, Convênio UESC/UFSB, 45600-970 Itabuna, Bahia, Brazil.

$15{ }^{e}$ Departamento de Ciências Agrárias e Ambientais, Universidade Estadual Santa Cruz, 45662-900

16 Ilhéus, Bahia, Brazil

$17{ }^{f}$ CNRS, UMR EcoFoG, AgroParisTech, Cirad, Inrae, Université des Antilles, Université de la 18 Guyane, Kourou, France.

$19{ }^{g}$ Cirad, Centre de Biologie pour la Gestion des populations, 34988 Montferrier-sur-Lez, France.

$20{ }^{h}$ Am Ehrenbach 8, 91356 Kirchehrenbach, Germany.

$21{ }^{i}$ Maestria de Entomologia, Universidad de Panamá, 080814 Panama City, Republic of Panama.

$22{ }^{j}$ Departamento de Biologia Geral, Universidade Federal de Viçosa, Brazil.

$23{ }^{k}$ Laboratório de Zoologia de Invertebrados, Departamento de Ciências Biológicas, Universidade

24 Estadual do Sudoeste da Bahia, 45200-000, Jequié, Bahia, Brazil

$25{ }^{l}$ Laboratoire écologie fonctionnelle et environnement, Université de Toulouse, CNRS, Toulouse INP,

26 Université Toulouse 3 - Paul Sabatier (UPS), Toulouse, France; 2 CNRS.

$27{ }^{m}$ School of Biological Sciences, The University of Western Australia, Crawley, Western Australia 28 6009, Australia. 
$29{ }^{n}$ CSIRO Health and Biosecurity, Centre for Environment and Life Sciences, Floreat, WA,

306014 Australia.

$31{ }^{o}$ Universität Würzburg, Department of Animal Ecology and Tropical Biology, 97070 Würzburg,

32 Germany.

$33{ }^{p}$ Laboratory of Ecology of Diseases \& Forests NUPEB/ICEB, Federal University of Ouro Preto

34 Campus Morro do Cruzeiro, Ouro Preto, MG, Brazil.

$35{ }^{q}$ Friedrich-Alexander-University of Erlangen-Nürenberg, Department of Biology, Erlangen,

36 Germany.

$37{ }^{r}$ California State Collection of Arthropods, CDFA, 3294 Meadowview Road, Sacramento, CA 95832,

$38 U S A$

$39{ }^{s}$ University of Victoria, Biology Department, PO Box 3020, Victoria, BC V8W 2Y2, Canada.

$40{ }^{t}$ University of South Bohemia, Faculty of Science, Department of Ecology and Conservation Ecology,

41 Ceske Budejovice, Czech Republic.

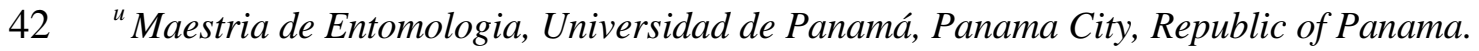

43

$44 *$ corresponding author at: Royal Belgian Institute of Natural Sciences, 29 rue Vautier, 1000

45 Brussels, Belgium. Tel: + 32262743 57. E-mail address: mleponce @ naturalsciences.be

46

47 Declaration of competing interest

$48 \quad$ No conflict of interest.

49 


\section{Graphical abstract}

51 Eleven sampling methods were used to study an entire rainforest ant assemblage at ground, canopy and understorey levels. Ant species composition differed between strata. Horizontal species turnover ( $\beta$ diversity) within forest strata was similar between sites. A functional traits approach revealed that the ant assemblage was mainly composed of generalist species with mid-sized colonies (group \#3, 31\% of the 405 species). However, ground- or litterdwelling species were also species-rich (\#1 \& 2), followed by arboreal ants (\#4) including ecologically important territorially dominant arboreal ants (\#5), and typical army ants (\#6).

Of the 11 sampling methods used, aerial flight interception traps placed alongside tree trunks (red triangles in the figure below) collected half of the ant species and reflected the vertical stratification of the ant species, demonstrating an interesting possibility for ant monitoring

61 programs.

62
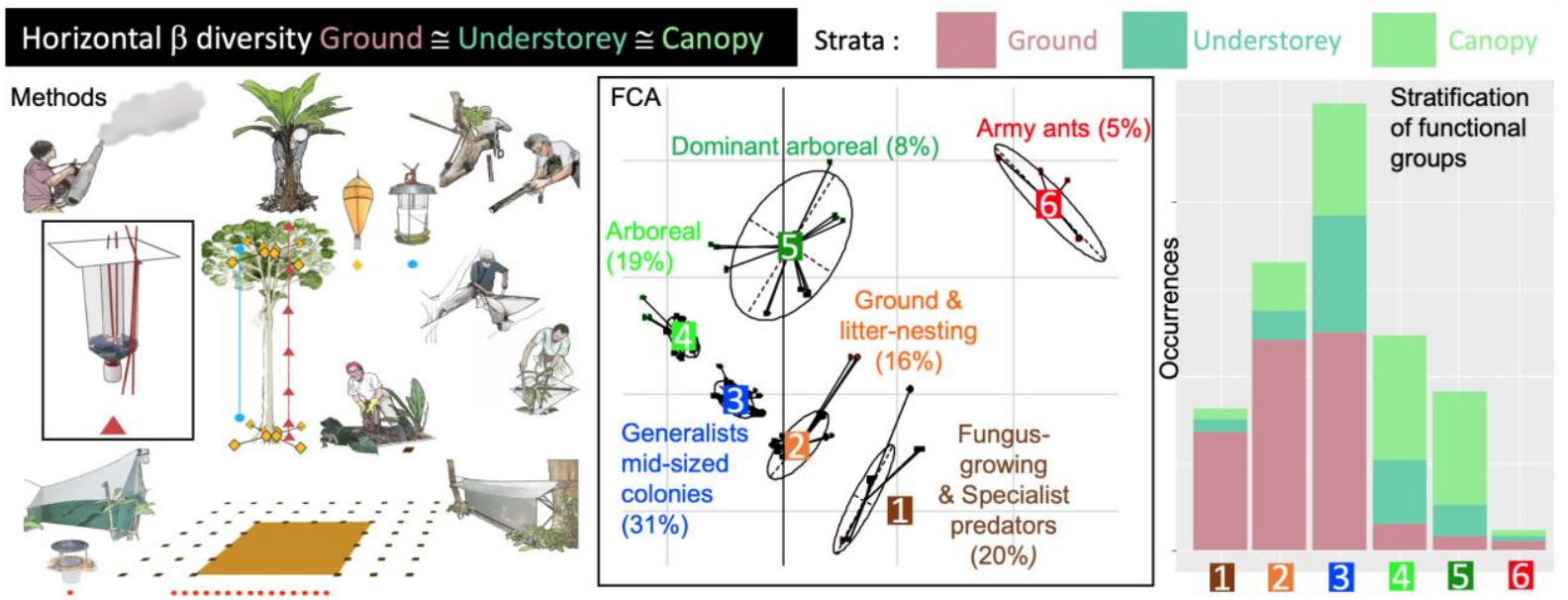
ABSTRACT

66

67

Ants are a major ecological group in tropical rainforests. Few studies in the Neotropics have documented the distribution of ants from the ground to the canopy, and none have included the understorey. A previous analysis of an intensive arthropod study in Panama, involving 11 sampling methods, showed that the factors influencing ant beta diversity (i.e., changes in assemblage composition) were, in decreasing order of importance, the vertical (height), temporal (season), and horizontal (geographic distance) dimensions. In the present study, we went one step further and aimed (1) to identify the best sampling methods to study the entire ant assemblage across the three strata, (2) to test if all strata show a similar horizontal beta diversity and (3) to analyze the functional structure of the entire ant assemblage. We identified 405 ant species from 11 subfamilies and 68 genera. Slightly more species were sampled in the canopy than on the ground; they belonged to distinct sub-assemblages. The understorey fauna was mainly a mixture of species found in the other two strata. The horizontal beta diversity between sites was similar for the three strata. About half of the ant species foraged in two (29\%) or three (25\%) strata. A single method, aerial flight interception traps placed alongside tree trunks, acting as arboreal pitfall traps, collected half of the species and reflected the vertical stratification. Using the functional traits approach, we observed that generalist species with mid-sized colonies were by far the most numerous (31\%), followed by ground- or litter-dwelling species, either specialists (20\%), or generalists (16\%), and arboreal species, either generalists (19\%) or territorially dominant (8\%), and finally army ants (5\%).

Our results reinforce the idea that a proper understanding of the functioning of ant assemblages requires the inclusion of arboreal ants in survey programs.

Keywords: horizontal beta diversity, vertical stratification, ant diversity, canopy, ant sampling methods, colony size, feeding habits, functional groups, nesting mode. 
The hot and humid climate of most intertropical areas promotes ecosystem productivity and so the formation of species-rich tropical rainforests characterized by large trees (30-50 m in height) and structured into three main strata (i.e., the canopy, understorey and ground) fostering a high plant diversity, including lianas and epiphytes (Morley, 2002; Nieder et al., 2001; Tymen et al., 2017; Wright, 2002). The canopy is exposed to high insolation and large differences in temperature and humidity between day and night, whereas at ground level climatic conditions are more stable, cooler and wetter (Parker 1995). This environmental heterogeneity induces a vertically stratified distribution of organisms adapted to local environmental conditions (Shaw 2004). Stratification in rainforests has been observed in a wide range of organisms, including vertebrates and invertebrates, and is responsible for spatial change in species composition (i.e., vertical beta diversity) (Basham et al. 2019, Basset et al. 2003). Horizontal beta diversity is also generalized and, for arthropods at least, is lower than vertical beta diversity in continuous vegetation types such as lowland tropical forests (Novotny et al. 2007, Basset et al. 2015). However, what is less well demonstrated is whether horizontal beta diversity is similar in the three forest strata. Differences could be generated by differences in habitat continuity, as the ground is continuous while the strata above the ground are discontinuous, which may limit species dispersal (Shaw 2004). This hypothesis is likely for amphibian assemblages, where a classic distance-decay (decrease in

110 compositional similarity with geographic distance) was observed in the canopy and

111 understorey, but not at ground level, indicating different rates of beta diversity between strata

112 (Basham et al. 2019). Alternatively, tolerance to microclimatic changes might also differ,

113 with ground-dwelling species living in a more stable environment than species above ground

114 (Madigosky, 2004). In contrast, when studying ants, Antoniazzi et al. 2021, found only a

115 distance-decay relationship at ground but not at canopy level. This result may have been 
116 affected by the sampling method, baits and visual searching, which only capture a fraction of

117 the ant assemblage, especially dominant species with large colonies which differ in their

118 biology and ecology between the ground and the canopy (Dejean, Corbara, Orivel, \&

119 Leponce, 2007).

120 Ants are one of the dominant animal groups in rainforests because of their colony size.

121 Some species have very large colonies (i.e., several thousands to several million individuals)

122 such as, at ground level, leaf-cutting ants which are major defoliators, army ants which are

123 major predators, and at canopy level, territorially dominant arboreal ants (territories

124 distributed in a mosaic pattern) that protect their host trees from defoliators (Brady, Fisher,

125 Schultz, \& Ward, 2014; Dejean et al., 2007; Hölldobler \& Wilson, 1994, 2011; Majer, 1993).

126 The development of large populations is made possible by the availability of energy-rich

127 resources derived from plants. Most ant species are partly herbivorous (primary consumers)

128 feeding on extrafloral nectar, food bodies, pollen, sap and leaves through fungiculture; they

129 are also ‘cryptic herbivores' feeding on hemipteran honeydew (Davidson et al., 2003; Rico-

130 Gray \& Oliveira, 2007; Tobin, 1994). Most of these ants are generalists as they also scavenge

131 dead animals and feces and capture different kinds of prey. Finally, some species are

132 predators, either generalists or specialists (Cerdá \& Dejean, 2011; Hölldobler \& Wilson, 133 1994).

134 Few studies in the Neotropics have documented ant distribution from the ground to the 135 canopy. Using a single method, baiting 20 trees from the base to the canopy, Yanoviak and 136 Kaspari (2000) recorded 48 ant species. Ryder Wilkie, Mertl, and Traniello (2010) obtained 137489 ant species in Ecuador with six methods (i.e., subterranean probes, pitfall traps, hand 138 collecting, Winkler devices, baiting and canopy fogging). Longino and Colwell (2020) noted 139539 species with seven methods (i.e., Malaise, light traps, Berlese, Winkler, baiting, hand 140 collecting and fogging). Finally, Antoniazzi et al. (2021) using baits and hand collection in 
141 the canopy and at ground level found 43 species on 10 trees. Unfortunately, none of the

142 studies included the understorey stratum, often dominated by palms in the Neotropics

143 (Popma, Bongers, \& Meave, 1988).

144 A previous analysis of an intensive arthropod study in Panama, involving 11 sampling

145 methods, showed that species turnover for arthropods, including ants, was driven primarily

146 by vertical and seasonal variation, and less by horizontal variation (Basset et al., 2015). We

147 analyze here this dataset in further detail to determine three approaches related to studying

148 ants. (1) The complementarity and the pertinence of the methods for studying the entire ant

149 assemblage, including the understorey species. (2) The validity of the null hypothesis that all

150 three strata show similar horizontal species turnover based on the best method for studying

151 the ant assemblages in multiple strata. We predicted the following. (a) The turnover will be

152 higher in the arboreal strata (canopy and understorey), representing islands of habitats

153 (Adams et al. 2017), than at ground level, a continuous habitat (Theunis et al., 2005). (b) The

154 local site conditions, whether abiotic or biotic, likely influence local ant species composition

155 (i.e., the non-random distribution of species diversity within-sites will be lower than between

156 sites, or distance-decay). (3) The functional structure of the entire forest ant assemblage

157 based on our survey and on a thorough review of the literature on the biology and ecology of

158 each species. Our prediction is that key ant groups, with large populations, will differ

159 according to the strata considered.

160

161 Material and methods

162

163 Study sites

164 This study was conducted in Panama during the IBISCA-Panama project in the 6,000

165 ha evergreen seasonal mixed rainforest in the San Lorenzo Protected Area which has been 
166 free of major disturbance for the past 200 years $\left(9^{\circ} 16^{\prime} \mathrm{N}, 79^{\circ} 58^{\prime} \mathrm{W} ; 130 \mathrm{~m}\right.$ a.s.1.). The climate

167 is moist tropical, with a mean annual rainfall of $3,139 \mathrm{~mm}$, and the daily mean temperature is

$16826^{\circ} \mathrm{C}$ (see STRI, 2017 for details). Ants were collected from 11 study sites that were

169 representative of the forest environment of the area, each measuring $40 \times 40 \mathrm{~m}$ and centered

170 around a $20 \times 20 \mathrm{~m}$ botanical plot (Basset et al., 2012, 2015). The present study was

171 conducted over a total surface area of $\approx 1.76$ ha and the sites were distributed from 24 to 1941

172 m apart (median: 700m). Field permits were granted by the Autoridad Nacional del Ambiente

173 of Panama.

174

175

Ant sampling methods

176 During the IBISCA-Panama project four surveys were conducted spanning the dry and 177 the wet seasons (September 2003 - November 2004) (Basset et al., 2012, 2015). Because the

178 San Lorenzo rainforest remains humid and experiences almost no loss of canopy cover during

179 the January-April dry season, the ground-level fauna is not thought to suffer much from

180 drought stress (see Roisin et al., 2006 for termites).

181 A combination of 11 sampling methods, resulting in an exceptionally large dataset, was used (Table 1; Fig.S1). (1) Berlese funnel. Three trees per site were sampled. For each tree, 16 soil cores of $15 \mathrm{~cm}^{3}$ were gathered at ground level $(\mathrm{n}=8)$ and at the bases of main branches $(\mathrm{n}=8)$ and placed in Berlese funnels for 2 days. (2) Winkler. This sampling was conducted on 51 quadrats of $1 \mathrm{~m}^{2}$ distributed at intervals of $5 \mathrm{~m}$ around each $20 \times 20 \mathrm{~m}$ plot. The leaf-litter

186 present within each quadrat was sifted and extracted during 48 hours by a Winkler extractor.

187 (3) Pitfall traps. At each study site 15 pitfall traps (424 ml) were buried in a line at $1.3 \mathrm{~m}$ intervals. They contained a solution of ethanol, salt and detergent and were examined after 3 days. (4) Aerial composite flight interception traps (aFIT). Each trap consisted of two vertical

190 perspex sheets $(60 \times 23 \mathrm{~cm})$ above a collecting funnel; a preserving jar was suspended from 
191 canopy branches by sturdy nylon ropes. The funnel functioned as a large arboreal pitfall collecting many ant workers and a few winged sexuals. Six to seven traps were placed in each of five sites at different heights $(0,1.3,7,14,21,28 \mathrm{~m}$ and in some cases $35 \mathrm{~m})$.

194 Because baiting experiments showed that canopy ants are generally present from $7 \mathrm{~m}$ above

195 the ground (Leponce et al., 2019), we considered that the traps installed above this height

196 intercepted ants from the canopy, whereas those placed $1.3 \mathrm{~m}$ above the ground rather 197 intercepted ants from the understorey and those placed at $0 \mathrm{~m}$ rather permitted ground-

198 dwelling ants to be captured. Left in place for 1 year, these traps were sampled every 10 days 199 yielding 1659 samples from the three forest strata. (5) Understorey Flight Interception Traps 200 (uFIT). Each uFIT consisted of a fine mesh screen ( 3 x $1 \mathrm{~m}$ that was left at each study site 201 during three consecutive 2-day-long periods). (6) Beating. Ants were dislodged by beating the foliage (three strong strokes using a stick) and collected on a square beating sheet measuring $0.4 \mathrm{~m}^{2}$. Beating was conducted in the canopy and the understorey at seven sites during the first survey and two sites during the second, third and fourth surveys (10 canopy and 10 understorey samples per site). A total of 560 beating samples were collected. (7) Palm tree inspection. Small Geonoma congesta H. Wendl. ex Spruce (Arecaceae) dominated the understorey. The clustering of their leaf petioles gathers litter, favoring the installation of ant nests (crown base at $\approx 1.5 \mathrm{~m}$ in height). During the first survey, 391 palm trees were monitored at three sites and the ants sheltered therein were collected using aspirators. (8)

210 Light traps. At each study site, three traps were installed in the understorey $2 \mathrm{~m}$ above the 211 ground and three others in the canopy at a height of 25-35 m. Replicated one night during four seasonal periods they resulted in a total of 96 samples. (9) Malaise traps. A Malaise trap

213 (2 x $1 \mathrm{~m}$ ) was operated during 10 days at eight sites during the first survey and occasionally

214 during the three other surveys yielding a total of 63 samples. (10) Climbers (branch-clipping).

215 During the first survey, climbers cut off two to four branches (diameter $>10 \mathrm{~cm}$ ) from the 
216 crown of 174 canopy trees situated in the vicinity of seven plots. Just after the branches had

217 fallen to the ground, the ants crawling on them or hiding in parts of nests were collected

218 using aspirators and forceps. Note that this method is particularly useful for capturing

219 territorially dominant arboreal ants (Dejean et al., 2018, 2019). (11) Fogging. A knockdown

220 insecticide (natural pyrethrum quickly broken down by UV rays) was sprayed up into the tree

221 crowns. Stunned arthropods fell onto six collecting sheets (5 x $4 \mathrm{~m})$. This method was used during the three surveys on 120 of the 174 previously mentioned trees.

Ant identification and voucher conservation

The ants were identified by comparing them with the collection kept at the

Myrmecology Laboratory, Cocoa Research Center, in Ilhéus, Bahia, Brazil and by consulting specialized literature. Bolton's catalogue nomenclature was used (Bolton, 2019).

Representative samples ("vouchers") of each species were deposited in this collection and at the Royal Belgian Institute of Natural Sciences (RBINS). This study focused on ant workers, but winged sexuals were identified when possible to increase taxonomic coverage but were excluded from the analyses on the stratification of ant assemblages.

Complementarity of each sampling method and its pertinence for studying the entire ant assemblage

To estimate the rate of species accumulation by each method (all strata pooled) or by strata (all methods pooled), species rarefaction curves were plotted on the species occurrences data matrices using the Mao Tau algorithm in EstimateS 9.1.0 software (Colwell, 2016) with 100 randomizations of the sampling order without replacement. Methods were grouped based on their compositional similarity according to the UPGMA algorithm with the Bray-Curtis similarity index available in the PAST 3.26 software. 
244 three strata, we used proportional Venn diagrams in which the area of each shape is

245 proportional to the number of species it includes.

To measure how species composition changed horizontally, we performed an additive partition of the species richness of each horizontal stratum (Barton et al., 2013, Veech et al., 250 2002): $\gamma=\alpha+\beta$ where $\gamma$ is the total species richness, $\alpha$ the average species richness within sites and $\beta$ the average difference in species richness between sites. This analysis was based on datasets from the three most efficient multi-strata sampling methods: aFITs (three strata), Berlese (two strata) and beating (two strata). We used the software PARTITION3 (Veech, \& Crist, 2009) to compare the observed diversity value to a corresponding null distribution (individual-based randomization method, 1000 randomizations). The mean observed richness is equal to the expected richness if the distribution of richness is spatially homogeneous. This allows us to test the significance of the observed value as either a significantly high or low value. In addition, we followed the approach developed by Baselga (2010) to separate beta diversity into its turnover (species change) and nestedness (species gain/loss) components.

260 The total compositional variation between assemblages was calculated using the Jaccard

261 pairwise dissimilarity index. For each combination of strata and method, pairwise beta

262 diversity measures were calculated using the "betapart" package (Baselga, \& Orme, 2012) in

263 R software (R core Team 2015). 
Based on previous studies of the nesting and feeding preferences of Neotropical rainforest ant species and the results obtained here on the distribution of morphospecies throughout the three forest strata (Appendix A1), we defined nominal categories for three functional traits (sensu largo, see Wong, Guénard, \& Lewis, 2019): (1) size of the colony (five categories: $<300$ individuals; 300-1,000; 1,000-10,000; 10,000-100,000; and >100,000); (2) nesting habits (seven categories: bivouac; subterranean; leaf-litter; plant-ants associated with myrmecophytes; arboreal nesting in hollow twigs; arboreal nesting in tree cavities; and arboreal building carton or silk nests); and (3) feeding habits (six categories: consumers of plant nectar or food bodies; honeydew feeders; fungus-growing leaf-cutters and debris collectors; scavengers; generalist predators; specialized predators), the whole resulting in 18 categories of functional traits.

We added the nesting strata (i.e., ground and litter, understorey and canopy) as three more traits obtaining a matrix of [405 ant species x 21 categories of traits]. The scores corresponding to the functional traits ranged from "0", indicating "no affinity" for a given trait category, to "3", indicating "high affinity". Information on the traits was structured using a Fuzzy-Coding technique (Chevenet, Dolédec, \& Chessel, 1994). A Fuzzy Correspondence Analysis (FCA) was conducted on this [ant species $x$ traits] matrix. We determined the optimal number of clusters (low variance within clusters and high variance between clusters) based on the majority rule after computing 23 clustering indices (Euclidean distance; Kmeans clustering method). To ease interpretation, bar plots were used to show the distribution of the samples from the different forest strata within clusters. These analyses were conducted with the ADE4, NbClust and ggplot2 packages in R software (R Development Core Team, 2015). 
291 Complementarity of each sampling method and its pertinence for studying the entire

292

293

294

295

296

297

298

299

300

301

302

303

304

305

306

307

308

309

310

311

312

313

\section{ant assemblage}

The combination of methods allowed us to record 405 ant species (11 subfamilies and 68 genera) in the $\approx 1.76$ ha of rainforest surveyed (Table 1 , Appendix A1). The rarefaction curve for the 11 sampling methods used indicates a near asymptote (Fig. $1 \mathrm{~A}$ ) as $\approx 81 \%$ of the estimated local species richness was recorded (Chao2 $=498$, CI95\% 459-564). The curves corresponding to the different methods used accumulated species at different rates, those for aerial and understorey FITs being similar, whereas palm trees accumulated the fewest species and light traps attracted only a few winged sexuals (Fig. 1B).

A cluster analysis showed that the methods fell into four groups according to the ant species collected (Fig. 2). The first group consists of soil and leaf-litter samples from the ground or the canopy collected with Berlese funnels and Winkler devices. The second group consists of understorey or canopy samples collected with Malaise traps, beating, fogging and by climbers. The third group consists of samples from all three strata obtained with aerial and understorey flight interception traps (aFITs and uFITs), pitfall traps and through palm tree inspection. Finally, the fourth group consists of light traps, less effective than the other methods.

The 10 most species-rich genera make up $50.9 \%$ of the occurrences of the 405 species recorded, whereas 11 ant species out of 405 account for more than one quarter of the occurrences (exactly $25.3 \%$ of 7,274 occurrences; Appendix A1). We collected few winged sexuals (100 occurrences) for 48 species of which eight were the sole sample of their species (Appendix A1). 
315 Winged sexuals were excluded from this analysis resulting in 397 ant species studied

316 here. Ant species composition showed a moderate vertical stratification. Globally, a total of 317253 species out of 397 were recorded on the ground, 199 in the understorey and 261 in the 318 canopy. The slightly higher presence of ants in the canopy compared to the ground and 319 understorey was confirmed by rarefaction (standardized richness for 1000 occurrences;

320 ground: $176 \pm 13$ species; understorey: 166 \pm 13 ; and canopy: 198 \pm 14 ) (Fig. 1C). However, 87 321 species (22\%) were sampled exclusively on the ground, 23 in the understorey (6\%), and 72 $322(18 \%)$ in the canopy (Fig. 3A). Overall, this indicates that certain species can patrol in two or 323 three strata, as confirmed by individual multi-strata collection methods (Fig. 3B-D). Aerial 324 FITs alone captured 53\% of the species present and reflected species stratification (Fig. 3B). 325 The ground stratum was dominated by the Myrmicinae, Ponerinae and Ectatomminae, while the canopy had a higher proportion of Formicinae, Dolichoderinae and Pseudomyrmicinae (Fig.4). An intermediate situation was found in the understorey.

Whatever the method considered, there was no significant difference between strata in horizontal beta diversity between sites, (aFIT: $\mathrm{F}(2,12)=0.39, \mathrm{P}=0.69$; Berlese: $\mathrm{t}=-0.84, \mathrm{P}=0.41$; beating: $t=0.29, P=0.78$ ) (Fig. 5). Furthermore, the observed $\beta$ diversity between sites was significantly higher than expected with randomized datasets, except in the understorey for

334 aFITs (Fig. 5), suggesting some site effect on horizontal species distribution. Species

335 turnover was the main contributor to beta diversity $(88 \pm 6 \%, n=7)$ while nestedness 336 contributed to $12 \pm 6 \%$ 
The FCA analysis based on the functional traits of the 405 ant species clearly delimited

340 six clusters (Fig. 6A). Cluster 1 groups together 83 ground- and litter-nesting species with

341 specialized feeding habits (e.g., specialized predators and fungus-growers) and small colonies

342 except for some fungus-growing species that have large to very large colonies. The 66

343 species in Cluster 2 are mostly ground and litter nesters with small to slightly larger colonies

344 (i.e., up to 1,000 individuals) and generalist feeding habits (e.g., scavenging, predatory and

345 feeding on sugary substances). Cluster 3 is comprised of 127 species most of which are

346 ground and litter nesters (e.g., Pheidole spp.) but some are arboreal that nest in preformed

347 cavities (e.g. Procryptocerus spp.; Pseudomyrmex spp.). Compared to the previous clusters

348 they are generalist feeders that most frequently feed on sugary substances, whereas the size of

349 the colonies can be relatively large (i.e., up to 10,000 individuals).

350 Comparatively, Cluster 4 groups together 77 arboreal species with mid-sized colonies

351 that nest in preformed cavities in the trees. Generalist feeders, they mostly exploit sugary

352 substances, particularly honeydew from the hemipterans they tend. By comparison, most of

353 the 31 species in Cluster 5 are characterized by their ability to build carton or silk nests, many

354 of them being territorially dominant arboreal ants with very large colonies. Exceptionally,

355 Wasmannia iheringi has small colonies. Finally, all 21 species in Cluster 6 are highly

356 predatory army ants with very large colonies that nest in bivouacs.

357 The ant species in these six clusters were noted in all forest strata, but to different

358 degrees as clusters 1, 2 and 3 dominated at ground level, cluster 3 in the understorey and

359 clusters 3,4 and 5 in the canopy (Fig. 6B). 
Discussion

In this Panamanian lowland rainforest, the estimated species richness was between 459 and 564 species (CI 95\%). This figure is lower than in Costa Rica and Amazonian Ecuador with 584-636 and 647-736 ant species, respectively (Longino \& Colwell, 2020; Ryder Wilkie et al., 2010). We sampled slightly more ant species in the canopy than on the ground (261 vs. 253 species) and their species assemblages were distinct with 87 species observed only on the ground and 72 in the canopy. The understorey ant fauna was mostly a mixture of species from the other two strata, but 23 species were specific to this stratum.

The stratification shown in the San Lorenzo rainforest for various groups of arthropods (Bourguignon, Leponce, \& Roisin, 2009; Roisin et al., 2006; Ribeiro, \& Basset, 2007; Basset et al., 2015) was also noted for ants for which some species were sampled only in one stratum (Fig. 1C and Fig. 3), in accordance with Ryder Wilkie et al. (2010) and Longino and Colwell (2020).

This stratification results from the following distinct environmental conditions in the three strata. At ground level, fallen leaves, wood and different debris are decomposed by detritivores (Stahl et al., 2013). Their abundance spurs ant diversification through predation involving omnivorous and strictly predatory species (Cerda \& Dejean, 2011; Hölldobler \& Wilson, 1994; Appendix A1). The ground layer also included leaf-cutting, fungus-growing ants which are preyed upon by specialized army ants (i.e., Nomamyrmex; Appendix A1) and detritivorous fungus-growing species preyed upon by other ants (i.e., Megalomyrmex as a social parasite of Attina; Appendix A1). Also, certain ant species feed on the honeydew of hemipterans attended on the roots of trees (Acropyga; Appendix A1).

The understorey was previously neglected in studies dealing with tropical rainforest ants. the species richness is intermediate between that for the ground and that for the canopy (176 
versus 166 and 198 ant species, respectively, Fig. 1C; Fig. 3). Small palm trees allow several ant species to nest in the litter between the clusters of their leaf petioles (Gibernau, Orivel, Delabie, Barabé, \& Dejean, 2007), whereas the workers of several generalist ground- and canopy-nesting species also foraged on understorey plants (Table 1 and Appendix A1).

In the canopy, the presence of populous territorially dominant arboreal ant colonies is possible via the presence of large numbers of attended honeydew-producing, sap-sucking hemipterans, whereas extrafloral nectar, rather produced by liana, is mostly exploited by nondominant ants, the latter forming the core of the species richness in this stratum (Blüthgen et al., 2000; Blüthgen \& Stork, 2007; Dejean et al., 2007). Food bodies in the canopy are mostly produced by myrmecophytic Cecropia and are the main, if not the only, food source for mutualistic plant-ants specifically associated with these trees such as Azteca constructor (Appendix A1).

Contrary to our predictions, which were based on the rationale that ground, understorey and canopy level assemblages were not subject to the same environmental variations because of differences in habitat continuity, we did not find any difference in horizontal beta diversity between strata. This result contrasts with the findings of Antoniazzi et al. (2021) who observed that horizontal beta diversity was different between the canopy and the ground in a Mexican lowland tropical rainforest. These authors collected ants on a limited number of trees during one-day sessions of baiting and hand collection. Thus, we cannot exclude that our results differ due to a different sampling approach (i.e., different spatiotemporal scale and

407 sampling coverage) (Barton et al. 2013). Furthermore, we observed that the beta diversity was greater than expected for a random spatial distribution of species (Veech, 2005). This suggests that general conditions at the local scale ( $40 \times 40 \mathrm{~m}$ site) had a prevailing effect on horizontal species distribution, increasing differences in species composition between sites

411 (Soininen et al., 2007). This could be due to local biotic or abiotic conditions affecting the 
412 overall ant species distribution across strata (Hortal et al., 2013, Kaspari et al., 2003, Klimes

413 et al., 2012). Another possibility is that the geographical scale of the study is too small (i.e.,

414 sites too close to each other) to show difference in beta diversity between strata. The beta

415 diversity was mainly driven by species turnover and much less by nestedness, indicating that

416 assemblages at species poor sites were not subsets of species rich sites.

417 The six clusters corresponding to the ants' functional traits were composed of ant species

418 collected from all three forest strata, but with some notable differences due to the interplay

419 between their nesting and foraging activities, and their colony size (Fig. 6). Cluster 1 is

420 characterized by specialist feeders including all fungus-growing ants of the New World

421 subtribe Attina (subfamily Myrmicinae; tribe Attini) plus specialized predators (e.g.,

422 Acanthognathus and Strumigenys prey on collembollans; Stegomyrmex, Discothyrea and

423 Proceratium on arthropod eggs; Leptogenys on diplopods; and Thaumatomyrmex on

424 myriapoda of the order Polyxenida) that are ground or litter nesters with small colonies. Yet,

425 some fungus-growing species have large to very large colonies (e.g., Cyphomyrmex

426 transversus, Trachymyrmex cornetzi, T. isthmicus and the leaf-cutting species of the genera

427 Acromyrmex and Atta) (see details in Appendix A1). Note that leaf-cutting ants are ecological 428 engineers and the main Neotropical defoliator (Hölldobler \& Wilson, 2011). Cluster 2 groups 429 ground- and litter-nesting species not belonging to Cluster 1 . The exceptions noted in the 430 canopy are colonies nesting in suspended soil (e.g., Hypoponera sp.08) or Solenopsis from 431 the subgenus Diplorhoptrum that are parasites of other ant species from which they steal 432 brood (see Appendix A1), some of them nesting in the forest canopy.

433 Cluster 3 is species rich because it groups together all generalist ant species with mid434 sized colonies, some of which are arboreal (Fig. 6). Cluster 4 corresponds to arboreal ants 435 with medium-sized colonies (Fig. 6), The colonies of Odontomachus hastatus noted in this 436 cluster nest in the litter accumulated in understorey palm trees or in association with hemi- 
epiphytes (Gibernau et al., 2007); other species nest in suspended soils in the canopy (e.g.,

Pheidole spp.), something facilitated by the presence of epiphytes (DaRocha et al., 2015,

Cluster 5 is composed of canopy-dwelling generalist feeders that build carton or silk nests (only W. iheringi has small colonies). Most are territorially dominant arboreal ants (e.g., genera Azteca, Cephalotes and Crematogaster) that protect their host trees from defoliators (Majer, 1993). Some workers were collected from the understorey and the ground as they were hunting or forming columns to move from one tree in their territory to another whose crowns are not in contact (Dejean et al., 2007, 2019).

Cluster 6 is composed of typical, nomadic army ants (Dorylinae) that organize raids from the soil to understorey plants, and certain of them (e.g., Eciton hamatum) even climb trees to hunt in their crowns, preying on the brood of social wasps and arboreal Dolichoderus and Camponotus colonies (Brady et al., 2014; Hölldobler \& Wilson, 1994, 2011). Although less species rich than the other clusters, with their large to very large colonies, army ants have a major impact on the rainforest ecosystem as they regulate other arthropods, including other ant taxa (McGlynn \& Poirson, 2012). Note that among the subfamily Dorylinae,

Cylindromyrmex meinerti and Syscia augustae, which prey on termites, have small colonies (de Andrade, 1998; Mackay and Mackay, 2002; Appendix 1), so that they belong to Cluster 2.

In conclusion, this study allowed us to link for the first time the diversity and distribution of ants and the functional ecology of the entire above-ground ant community in a lowland

458 Neotropical forest. Generalist species with mid-sized colonies were the most frequent.

459 Ground- or litter-dwelling species with a specialized diet were also species rich, whereas this 460 was not the case for the ecologically important territorial dominant arboreal ants, leaf-cutting 461 ants and typical army ants. Half of the species foraged in more than one stratum. Slightly 
more species were present in the canopy than at ground level and an intermediate number of

463

464

465

466

467

468

469

470

471

472

473

474

475

476

477

478

479

480

481

482

483

484

485

486

species was found in the understorey. At the scale of a site, local conditions appear to

influence the horizontal distribution of species, but there does not seem to be a different horizontal species turnover between strata. Finer scale studies are needed to determine in more detail which factors may be responsible for this pattern (Klimes et al., 2012). When used for a prolonged period of time, aerial flight interception traps, acting as pitfall traps, collected half of the species in the three forest layers and may be useful for programs monitoring the entire ant assemblage in future studies. By complementing them with subterranean pitfall traps, the hypogeous ant fauna might be even better documented (Wong \& Guénard, 2017). Overall, this study emphasizes the importance of comprehensive, multistrata surveys and thorough reviews of methods to better understand the functioning of ant assemblages in tropical rainforest environments.

\section{Acknowledgments}

IBISCA-Panama is an initiative of Pro-Natura International, Océan Vert, the University Blaise Pascal, Clermont-Ferrand, France, the University of Panama, and the Smithsonian Tropical Research Institute (STRI). We thank N. Springate, R. Kitching, L. Fagan, F. Odegaard for their contribution to the collection of ant specimens. I. Bachy helped with the design of figures. We are grateful to J. Herrera, E. Andrade, M. Samaniego, S.J. Wright, N. Baiben, S. Bechet, J. Belleguic, T. Aubert, K. Jordan, G. Ebersolt, D. Cleyet-Marrel, L. Pyot, O. Pascal, P. Basset, and E. Bauhaus who helped with logistics in the field and to A. Yockey for proofreading the manuscript. We also wish to thank two reviewers for their useful suggestions and J. Veech for providing the PARTITION 3 software. 
488 Core funding was provided by SolVin-Solvay SA, STRI, the United Nations Environment 489 Program, the Smithsonian Institution (Walcott Fund), the European Science Foundation, and 490 the Global Canopy Program. YB, a member of the Sistema Nacional de Investigacion of the

491 SENACYT in Panama together with HB and EM, acknowledges the help of the Smithsonian

492 Tropical Research Institute and Maestría Centroamericana de Entomología, Universidad de 493 Panamá, during the preparation of the IBISCA-Panama project. YB received financial 494 support through a mobility grant Universidad de Panamá-RBINS, a Czech Science 495 Foundation GAČR grant 20-31295S, the European Social Fund, the Czech Ministry of 496 Education CZ.1.07/2.3.00/20.0064 and the U.S. National Science Foundation DEB-0841885.

497 SPR and JHCD received financial support from the CNPq. JO received financial support 498 from an "Investissement d'Avenir" grant managed by the French Agence Nationale de la 499 Recherche (CEBA, ref. ANR-10- LABX-25-01). The funding institutions had no role in 500 study design, data collection and analysis, decision to publish, or preparation of the 501 manuscript.

\section{References}

Adams, B. J., Schnitzer, S. A., \& Yanoviak, S. P. (2017). Trees as islands: canopy ant species richness increases with the size of liana-free trees in a Neotropical forest. Ecography, 40, 9, 1067-1075. https://dx.doi.org/10.1111/ecog.02608.

Adams, B. J., Schnitzer, S A., \& Yanoviak, S. P. (2019). Connectivity explains local ant community structure in a Neotropical forest canopy: a large-scale experimental approach. Ecology, 100, e02673. https://dx.doi.org/10.1002/ecy.2673.

510 Antoniazzi, R., Guevara, R., García- Franco, J., Janda, M., Leponce, M., \& Dáttilo, W. (2021). Environmental drivers of ant dominance in a tropical rainforest canopy at 

https://doi.org/10.1111/een.12988.

514 Barton, P. S., Cunningham, S. A., Manning, A. D., Gibb, H., Lindenmayer, D. B., \& Didham, R. K. (2013). The spatial scaling of beta diversity. Global Ecology and Biogeography, 22, 639-647. https://dx.doi.org/10.1111/geb.12031.

Baselga, A. (2010). Partitioning the turnover and nestedness components of beta diversity. Global Ecology and Biogeography, 19, 134-143. https://doi.org/10.1111/j.14668238.2009.00490.x.

Baselga, A., \& Orme C. D. L. (2012). Betapart: an R package for the study of beta diversity: Betapart package. Methods in Ecology and Evolution, 3, 808-812. https://doi.org/10.1111/j.2041-210X.2012.00224.X

Basham, E. W., Seidl, C. M., Andriamahohatra, L. R., Oliveira, B. F., \& Scheffers, B. R. (2019). Distance-decay differs among vertical strata in a tropical rainforest. Journal of Animal Ecology, 88, 114-124. https://dx.doi.org/10.1111/1365-2656.12902.

Basset, Y., Kitching, R., Novotny, V., \& Miller, S. (2003). Arthropods of Tropical Forests: Spatio-Temporal Dynamics and Resource Use in the Canopy. Cambridge: Cambridge University Press.

Basset, Y., Cizek, L., Cuenoud, P., Didham, R., Guilhaumon, F., Missa, O., et al. (2012). Arthropod diversity in a tropical forest. Science, 338, 1481-1484. https://dx.doi.org/10.1126/science.1226727.

Basset, Y., Cizek, L., Cuénoud, P., Didham, R. K., Novotny, V., Ødegaard, F., et al. (2015). Arthropod distribution in a tropical rainforest: tackling a four-dimensional puzzle. PLoS ONE, 10, e0144110. https://doi.org/10.1371/journal.pone.0144110. 
535 Blüthgen, N., \& Stork, N. E. (2007). Ant mosaics in a tropical rainforest in Australia and

536

537

538

539

540

541

542

543

544

545

546

547

548

549

550

551

552

553

554

555

556

557

558 elsewhere: a critical review. Austral Ecology, 32, 93-104. https://dx.doi.org/10.1111/j.1442-9993.2007.01744.x.

Blüthgen, N., Verhaagh, M., Goitía, W., Jaffé, K., Morawetz, W., \& Barthlott, W. (2000). How plants shape the ant community in the Amazonian rainforest canopy: the key role of extrafloral nectaries and homopteran honeydew. Oecologia, 125, 229-240. https://dx.doi.org/10.1007/s004420000449.

Bolton, B. (2019). An online catalog of the ants of the world. https://antcat.org.

Bourguignon, T., Leponce, M., \& Roisin, Y. (2009). Insights into the termite assemblage of a Neotropical rainforest from the spatio-temporal distribution of flying alates. Insect Conservation and Diversity, 2, 153-162. https://dx.doi.org/10.1111/j.17524598.2009.00055.x.

Brady, S. G., Fisher, B. L., Schultz, T. R., \& Ward, P. S. (2014). The rise of army ants and their relatives: diversification of specialized predatory doryline ants. $B M C$ Evolutionary Biology, 14, 93-107. https://dx.doi.org/10.1186/1471-2148-14-93.

Cerdá, X., \& Dejean, A. (2011). Predation by ants on arthropods and other animals. In C. Polidori (Ed.), Predation in the Hymenoptera: An evolutionary perspective (pp. 3978). Kerala: TransWorld Research Network.

Chevenet, F., Dolédec, S., \& Chessel, D. (2006). A fuzzy coding approach for the analysis of long-term ecological data. Freshwater Biology, 31, 295-309. https://dx.doi.org/10.1111/j.1365-2427.1994.tb01742.x.

Colwell, R. (2016). EstimateS: Statistical estimation of species richness and shared species from samples. Version 9.1.0. User's Guide and application. http://purl.oclc.org/estimates. 
559 DaRocha, W., Neves, F., Dáttilo, W., \& Delabie, J. H. C. (2016). Epiphytic bromeliads as key components for maintenance of ant diversity and ant-bromeliad interactions in agroforestry system canopies. Forest Ecology and Management, 372, 128-136. https://dx.doi.org/10.1016/j.foreco.2016.04.011.

DaRocha, W., Ribeiro, S., Neves, F., Fernandes, G., Leponce, M., \& Delabie, J. H. C. (2015). How does bromeliad distribution structure the arboreal ant assemblage (Hymenoptera: Formicidae) on a single tree in a Brazilian Atlantic forest agroecosystem? Myrmecological News, 21, 83-92.

Davidson, D., Cook, S., Snelling, R., \& Chua, T. (2003). Explaining the abundance of ants in lowland tropical rainforest canopies. Science, 300, 969-972. https://dx.doi.org/10.1126/science.1082074.

de Andrade, M. L. (1998). Fossil and extant species of Cylindromyrmex (Hymenoptera: Formicidae). Revue Suisse de Zoologie, 105, 581-664.

Dejean, A., Compin, A., Delabie, J., Azémar, F., Corbara, B., \& Leponce, M. (2019). Biotic and abiotic determinants of the formation of ant mosaics in primary Neotropical rainforests. Ecological Entomology, 44, 560-570. https://dx.doi.org/10.1111/een.12735.

Dejean, A., Corbara, B., Orivel, J., \& Leponce, M. (2007). Rainforest canopy ants: The implications of territoriality and predatory behavior. Functional Ecosystems and Communities, 1, 105-120. https://doi.org/10.1093/biolinnean/bly125.

Dejean, A., Orivel, J., Leponce, M., Compin, A., Delabie, J., Azémar, F., \& Corbara, B. (2018). Ant-plant relationships in the canopy of an Amazonian rainforest: The presence of an ant mosaic. Biological Journal of the Linnean Society, 125, 344-354. https://dx.doi.org/10.1093/BIOLINNEAN/BLY125. 
583

584

585

586

587

588

589

590

591

592

593

594

595

596

597

598

599

600

601

602

603

604

605

606

Gibernau, M., Orivel, J., Delabie, J. H. C., Barabé, D., \& Dejean, A. (2007). An asymmetrical relationship between an arboreal ponerine ant and a trash- basket epiphyte (Araceae). Biological Journal of the Linnean Society, 91, 341-346. https://dx.doi.org/10.1111/j.1095-8312.2007.00799.x.

Hölldobler, B., \& Wilson, E. O. (1994). Journey to the ants: a story of scientific exploration. Cambridge, Massachusetts: Belknap Press of Harvard University Press.

Hölldobler, B., \& Wilson, E. O. (2011). The leafcutter ants. Civilization by instinct. New York: W.W. Norton \& Company.

Hortal, J., Roura-Pascual, N., Sanders, N. J., \& Rahbek, C. (2010). Understanding (insect) species distributions across spatial scales. Ecography, 33, 51-53. https://dx.doi.org/10.1111/j.1600-0587.2009.06428.x.

Kaspari, M., Yuan, M., \& Alonso, L. (2003). Spatial grain and the causes of regional diversity gradients in ants. The American Naturalist, 161, 459-477. https://dx.doi.org/doi: 10.1086/367906.

Klimes, P., Idigel, C., Rimandai, M., Fayle, T. M., Janda, M., Weiblen, G. D., \& Novotny, V. (2012). Why are there more arboreal ant species in primary than in secondary tropical forests? Journal of Animal Ecology, 81, 1103-1012. https://dx.doi.org/1103-1112. 10.1111/j.1365-2656.2012.02002.x.

Leponce, M., Delabie, J. H. C., Jacquemin, J., Martin, M. C., Dejean, A. (2019). Treedwelling ant survey (Hymenoptera, Formicidae) in Mitaraka, French Guiana. Zoosystema, 41, 163-179. https://doi.org/10.5252/zoosystema2019v41a10.

Longino, J. T., \& Colwell, R. (2020). The arboreal ants of a Neotropical rain forest show high species density and comprise one third of the ant fauna. Biotropica, 52, 675-685. https://dx.doi.org/10.1111/btp.12772. 
607 Longino, J. T., \& Nadkarni, N. M. (1990). A comparison of ground and canopy leaf litter ants 608 (Hymenoptera: Formicidae) in a Neotropical montane forest. Psyche, 97, 81-93. https://dx.doi.org/10.1155/1990/36505.

MacKay, W. P., MacKay, E. E. (2002). The Ants of New Mexico. Lewiston: Edwin Mellen Press.

612 Madigosky, S. R. (2004). Tropical Microclimate Considerations. In: M.D. Lowman, \& H.B. 613 Rinker (Eds.), Forest Canopies: Second Edition (pp. 24-48). Burlington: Elsevier $614 \quad$ Academic Press.

Majer, J. D. (1993). Comparison of the arboreal ant mosaic in Ghana, Brazil, Papua New Guinea and Australia - its structure and influence on ant diversity. In: J. LaSalle, \& I.D. Gauld (Eds.), Hymenoptera and biodiversity (pp. 115-141). Oxford: CAB International.

McGlynn, T. P., \& Poirson, E. K. (2012). Ants accelerate litter decomposition in a Costa Rican lowland tropical rain forest. Journal of Tropical Ecology, 28, 437-443. http://dx.doi.org/10.1017/S0266467412000375.

Morley, R. J. (2002). Origin and evolution of tropical rain forests. Chichester: John Wiley and Sons.

Nieder, J., Prosperí, J., \& Michaloud, G. (2001). Epiphytes and their contribution to canopy diversity. Plant Ecology, 153, 51-63. https://dx.doi.org/10.1023/A:1017517119305. Darrow, K., Stewart, A. J., Auga, J., Isua, B., Molem, K., Manumbor, M., Tamtiai, E., Mogia, M., \& Weiblen, G. D. (2007). Low beta diversity of herbivorous insects in tropical forests. Nature, 448, 692-695. https://dx.doi.org/10.1038/nature06021.

630 Parker, G.G. (1995). Structure and microclimate of forest canopies. In: M.D. Lowman, \& N. M. Nadkarni (Eds.), Forest Canopies (pp. 73-106). San Diego: Academic Press. 
632 Popma, J., Bongers, F., \& Meave, J. (1988). Patterns in the vertical structure of the tropical

633

634

635

636

637

638

639

640

641

642

643

644

645

646

647

648

649

650

651

652

653

654 lowland rain forest of Los Tuxtlas, Mexico. Plant Ecology, 74, 81-91. https://dx.doi.org/10.1007/BF00045615.

R Development Core Team. (2015). R: A language and environment for statistical computing. R Foundation for Statistical Computing, Vienna. http://www.Rproject.org/.

Ribeiro, S.P., \& Basset, Y. (2007). Gall-forming and free-feeding herbivory along vertical gradients in a lowland tropical rainforest: The importance of leaf sclerophylly. Ecography, 30, 663-672. https://dx.doi.org/10.1111/j.2007.0906-7590.05083.x.

Rico-Gray, V. \& Oliveira, P. S. (2007). The Ecology and Evolution of Ant-Plant Interactions. Chicago: University of Chicago Press.

Roisin, Y., Dejean, A., Corbara, B., Orivel, J., Samaniego, M., \& Leponce, M. (2006). Vertical stratification of the termite assemblage in a Neotropical rainforest. Oecologia, 149, 301-311. https://dx.doi.org/10.1007/s00442-006-0449-5.

Ryder Wilkie, K. T., Mertl, A. L., \& Traniello, J. F. A. (2010). Species diversity and distribution patterns of the ants of Amazonian Ecuador. PLoS ONE, 5, e13146. https://dx.doi.org/10.1371/journal.pone.0013146.

Shaw, D. C. (2004). Vertical organization of canopy biota. In: M. D. Lowman, \& H. B. Rinker (Eds.), Forest Canopies: Second Edition (pp. 73-101). Burlington: Elsevier Academic Press.

Soininen, J., McDonald, R., \& Hillebrand, H. (2007). The distance decay of similarity in ecological communities. Ecography, 30, 3-12. https://dx.doi.org/10.1111/j.2006.0906-7590.04817.x. 
655 Stahl, C., Herault, B., Rossi, V., Burban, B., Bréchet, C., \& Bonal, D. (2013). Depth of soil

656

657

658

659

660

661

662

663

664

665

666

667

668

669

670

671

672

673

674

675

676

677

678 water uptake by tropical rainforest trees during dry periods: does tree dimension matter? Oecologia, 173, 1191-1201. https://dx.doi.org/10.1007/s00442-013-2724-6.

STRI. (2017). Physical monitoring program.

https://biogeodb.stri.si.edu/physical_monitoring/research/sherman.

Theunis, L., Gilbert, M., Roisin, Y., \& Leponce, M. (2005). Spatial structure of litterdwelling ant distribution in a subtropical dry forest. Insectes Sociaux, 52, 366-377. https://dx.doi.org/10.1007/s00040-005-0822-0.

Tobin, J. E. (1994). Ants as primary consumers: diet and abundance in the Formicidae. In: J.H. Hunt, C.A. Napela (Eds.), Nourishment and evolution in insect societies (pp. 279-307). Boulder: Westview Press.

Tymen, B., Vincent, G., Courtois, E. A., Heurtebize, J., Dauzat, J., Marechaux, I., \& Chave, J. (2017). Quantifying micro-environmental variation in tropical rainforest understory at landscape scale by combining airborne LiDAR scanning and a sensor network. Annals of Forest Science, 74, 32-45. https://dx.doi.org/10.1007/s13595-017-0628-z.

Veech, J. A. (2005). Analyzing patterns of species diversity as departures from random expectations. Oikos, 108, 149-155.

Veech, J. A., \& Crist, T. O. (2009). PARTITION: software for hierarchical partitioning of species diversity, version 3.0. https://ecology.wp.txstate.edu/diversity-partitioning/.

Veech, J. A., Summerville, K. S., Crist, T. O., \& Gering, J. C. (2002). The additive partitioning of species diversity: recent revival of an old idea. Oikos, 99, 3-9.

Wong, M. K. L., \& Guénard, B. (2017). Subterranean ants: summary and perspectives on field sampling methods, with notes on diversity and ecology (Hymenoptera: Formicidae). Myrmecological News, 25, 1-16. 
679 Wong, M. K. L., Guénard, B., \& Lewis, O. T. (2019). Trait-based ecology of terrestrial $680 \quad$ arthropods. Biological Reviews of Cambridge Philosophical Society, 94, 999-1022. 681 https://dx.doi.org/10.1111/brv.12488.

682 Wright, J. S. (2002). Plant diversity in tropical forests: a review of mechanisms of species $683 \quad$ coexistence. Oecologia, 130, 1-14. https://dx.doi.org/10.1007/s004420100809.

684 Yanoviak, S., \& Kaspari, M. (2000). Community structure and the habitat templet: ants in the 685 tropical forest canopy and litter. Oikos, 89, 259-266.

686 https://dx.doi.org/10.1034/j.1600-0706.2000.890206.x.

687 
Table 1

691 Sampling effort used to collect ants in the three strata of the San Lorenzo rainforest with the number

692 of samples for each method, the number of samples containing ants (also expressed as a percentage),

693 the number ant species collected, the number of sites where these methods were used, the number of

694 seasonal replicates, and the total number of trapping days. Abbreviations: aFIT: aerial composite

695 Flight Interception Trap installed every 7 meters along a tree trunk (plus one at $1.3 \mathrm{~m}$ above ground);

696 uFIT: understorey Flight Intercept Trap.

697

698 Fig. 1. Sample-based rarefaction curves for the 11 sampling methods used in the San Lorenzo

699 protected area (405 ant species and 4,547 samples). A) Global view, all strata combined; B) Close-up;

700 C) Individual-based rarefaction (all methods pooled, winged sexuals excluded; 397 species) showing

701 the number of species found in each strata.

702

703 Fig. 2. Faunal similarity between the ant species captured using the different sampling methods for 704 the three forest levels.

705

706 Fig. 3. Proportional Venn diagram of the number of species collected from the ground, understorey

707 and canopy levels showing both differences and overlaps between the three strata (based on workers;

708 winged sexuals excluded). A) The combined 11 sampling methods resulted in 397 ant species being

709 captured. B) Aerial FITs, acting as pitfall traps, captured 209 species combined from the ground (traps

710 at $0 \mathrm{~m}$, with buried collector funnel), the understorey (traps suspended $1.3 \mathrm{~m}$ above the ground) and

711 the canopy (traps at 7, 14, 21, 28, $35 \mathrm{~m}$ ). C) Beating enabled 67 species to be sampled. D) Berlese

712 funnels resulted in 97 species being captured. Values indicate the number of ant species in each

713 category.

714 
715 Fig. 4. Proportion of ant subfamilies observed in the three strata and by stratum-specific methods

716 (Winkler, palm inspection, fogging, respectively). Subfamily abbreviations: DOLI: Dolichoderinae,

717 DORY: Dorylinae, ECTA: Ectatomminae, FORM: Formicinae, HETE: Heteroponerinae, MYRM:

718 Myrmicinae, PARA: Paraponerinae; PONE: Ponerinae; PROC: Proceratiinae; PSEU:

719 Pseudomyrmecinae.

720

721 Fig. 5. Comparison of the horizontal species turnover within each stratum for species collected either

722 with aFITs, Berlese or beating. Total (gamma) diversity for each stratum was decomposed into

723 average alpha (local) diversity of 40x40m sites and the beta diversity between sites. The observed and

724 expected contribution of alpha and beta diversity are provided. An asterisk $\left({ }^{*}\right)$ refers to significant

725 differences between observed and expected values based on 1000 randomizations of the dataset.

726

727 Fig. 6 Fuzzy Correspondence Analysis (FCA) of functional traits composition corresponding to the

728405 ant species recorded in this study. A. Ordination of the ant species on the two first axes of the

729 FCA. The percentage of species in each cluster is indicated in brackets. B. Ordination of the

730 functional trait modalities on the two first axes of the FCA. C. Distribution of the ants from the six

731 clusters defined in Fig. 6A among the rainforest strata based on their occurrence in samples.

732 

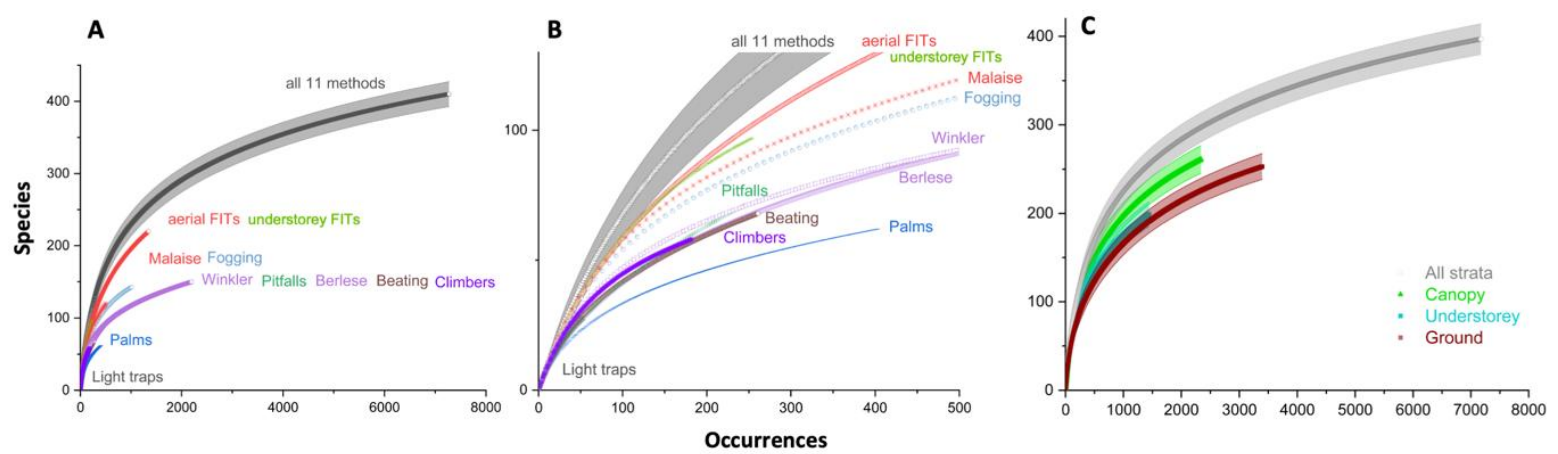

735 Fig. 1. Sample-based rarefaction curves for the 11 sampling methods used in the San Lorenzo

736 protected area (405 ant species and 4,547 samples). A) Global view, all strata combined; B) Close-up;

737 C) Individual-based rarefaction (all methods pooled, winged sexuals excluded; 397 species) showing

738 the number of species found in each strata. 


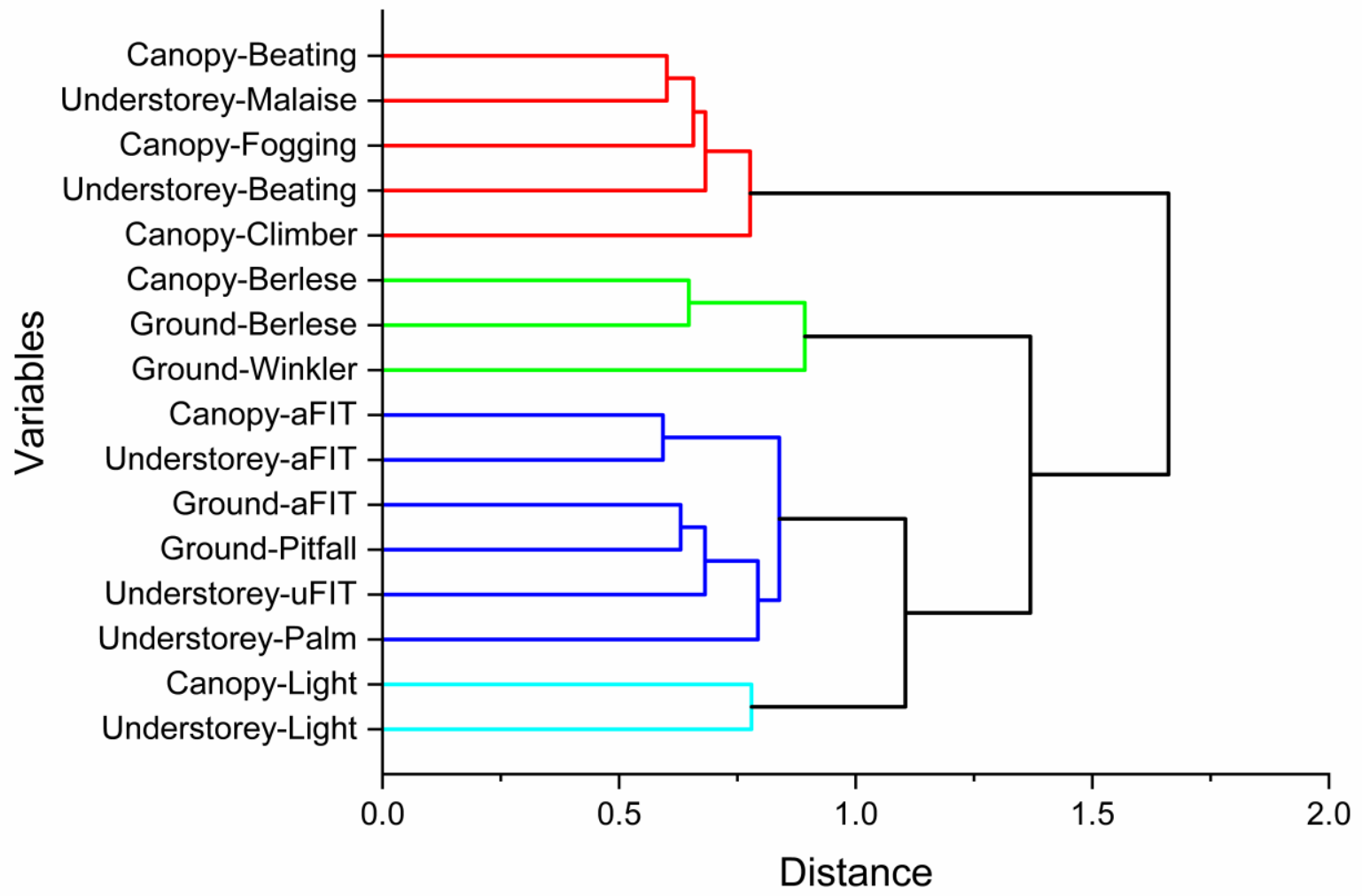

740

741 Fig. 2. Faunal similarity between the ant species captured using the different sampling methods for

742 the three forest levels 


\section{Canopy \\ Understorey \\ Ground}

A

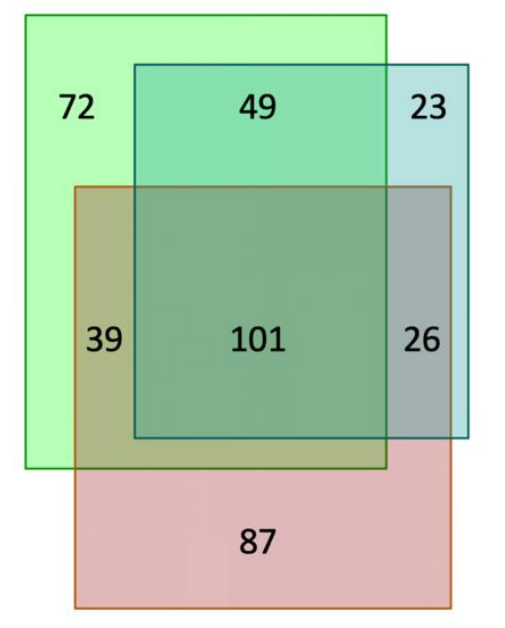

B

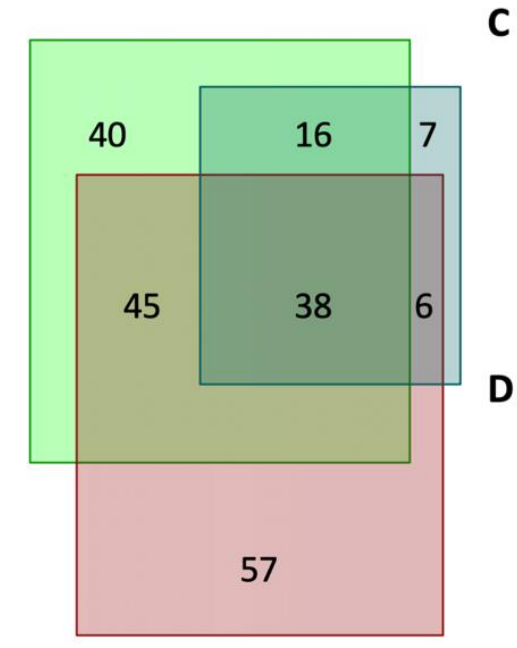

C

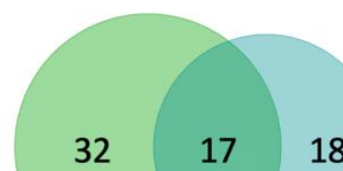

18

25

28

746 Fig. 3. Proportional Venn diagram of the number of species collected from the ground, understorey

747 and canopy levels showing both differences and overlaps between the three strata (based on workers).

748 A) The combined 11 sampling methods resulted in 397 ant species being captured. B) Aerial FITs,

749 acting as pitfalls, captured 209 species combined from the ground (traps at $0 \mathrm{~m}$, with buried collector

750 funnel), the understorey (traps suspended $1.3 \mathrm{~m}$ above the ground) and the canopy (traps at 7, 14, 21,

$75128,35 \mathrm{~m})$. C) Beating captured 67 species. D) Berlese funnels captured 97 species. Values indicate

752 the number of ant species in each category. 

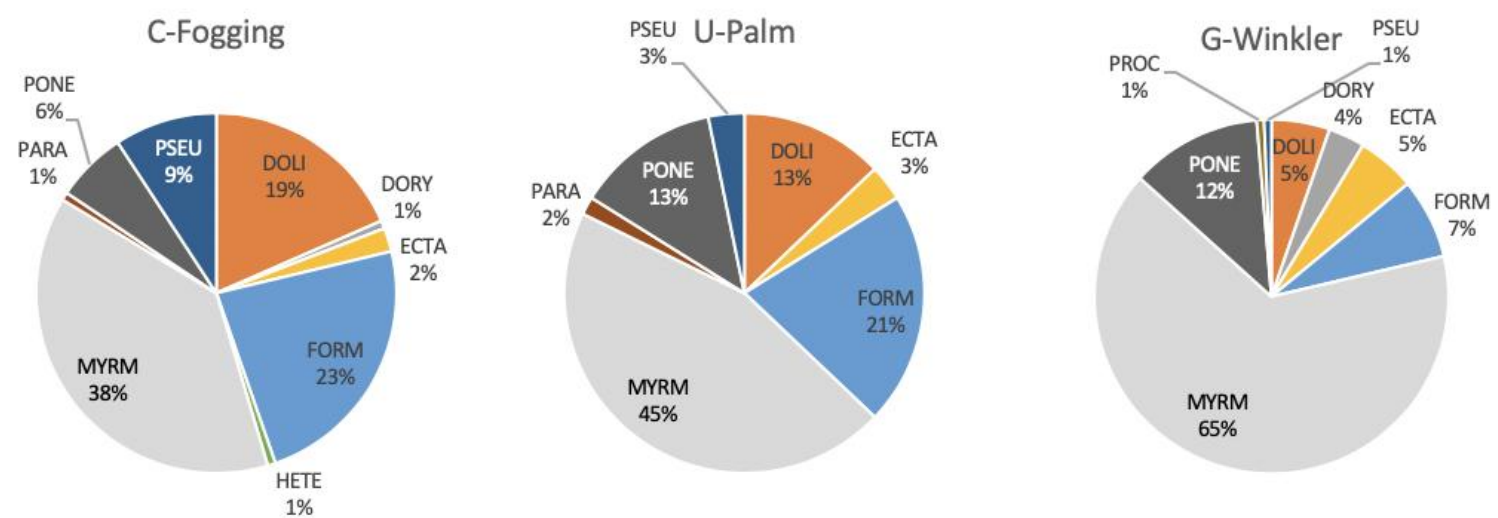

754

755 Fig. 4. Proportion of ant subfamilies observed in the three strata (C: Canopy, U: Understory, G:

756 Ground) and by stratum-specific methods (fogging, palm inspection, Winkler, respectively).

757 Subfamily abbreviations: DOLI: Dolichoderinae, DORY: Dorylinae, ECTA: Ectatomminae, FORM:

758 Formicinae, HETE: Heteroponerinae, MYRM: Myrmicinae, PARA: Paraponerinae; PONE:

759 Ponerinae; PROC: Proceratiinae; PSEU: Pseudomyrmecinae. 


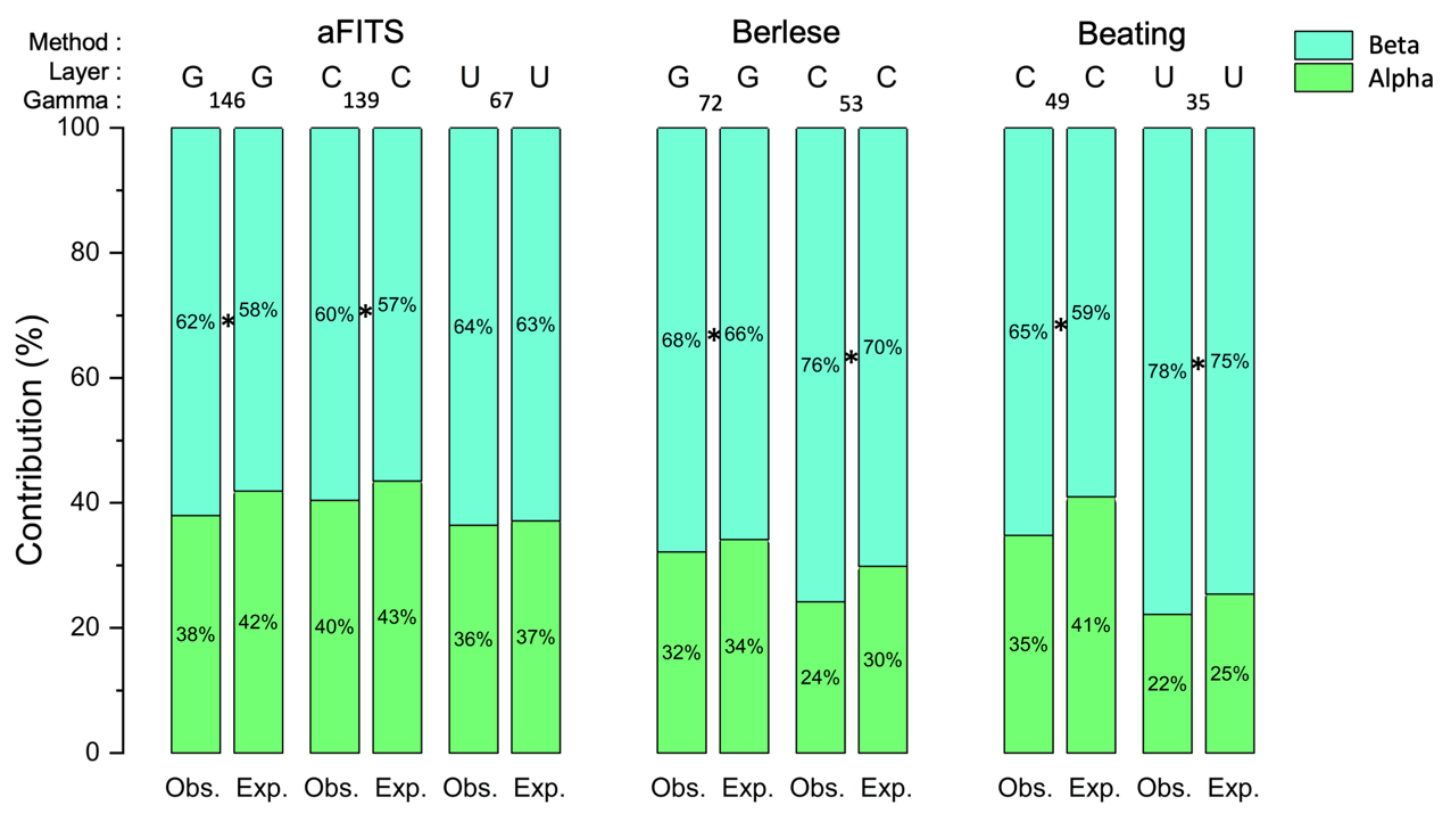

762 Fig. 5. Comparison of the horizontal species turnover within each stratum for species collected either

763 with aFITs, Berlese or beating. Total (gamma) diversity for each stratum was decomposed into

764 average alpha (local) diversity of 40x40m sites and the beta diversity between sites. The observed and

765 expected contribution of alpha and beta diversity are provided. An asterisk (*) refers to significant

766 differences between observed and expected values based on 1000 randomizations of the dataset. 


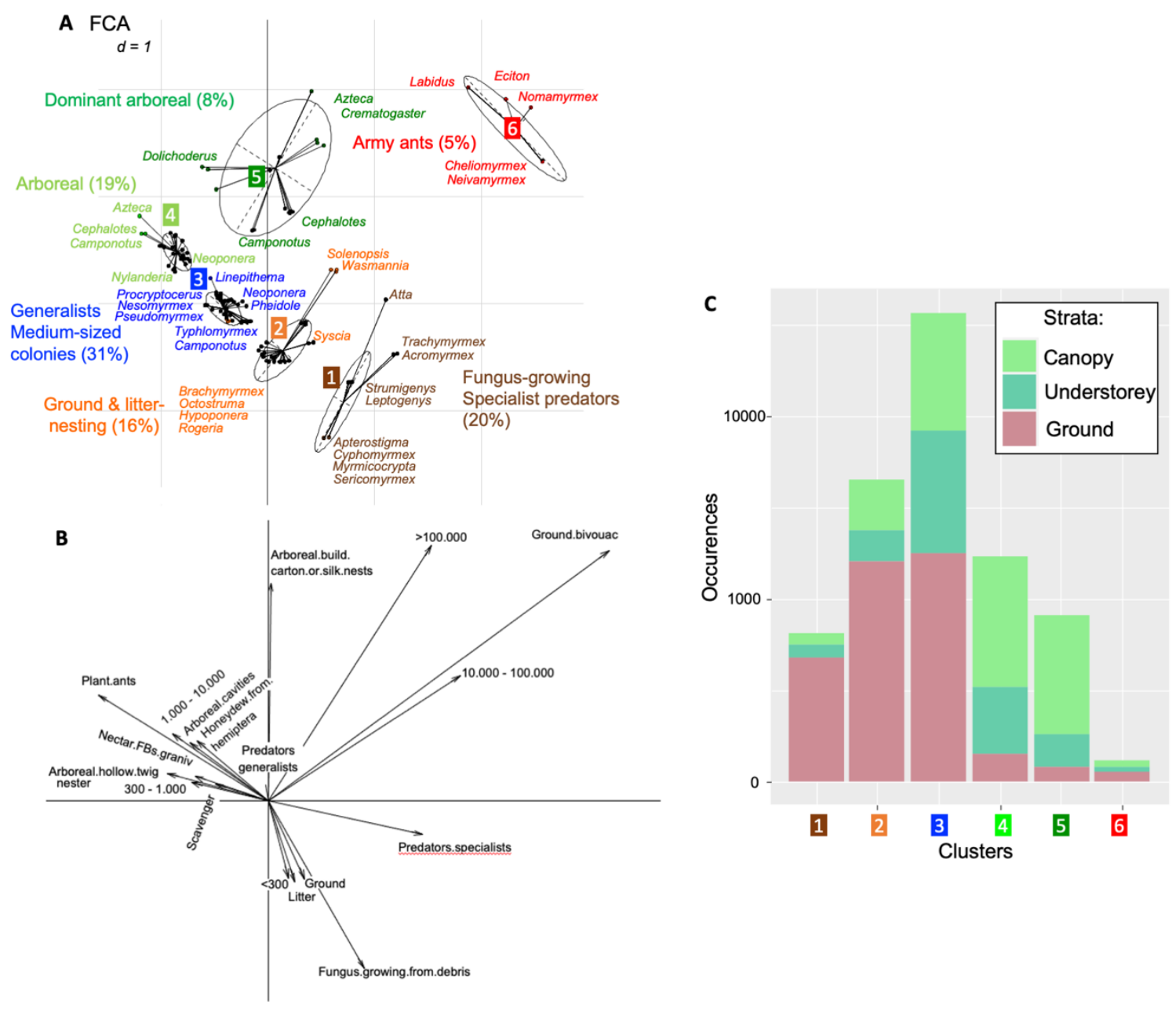

769 Fig. 6 Fuzzy Correspondence Analysis (FCA) of functional traits composition corresponding to the

770405 ant species recorded in this study. A. Ordination of the ant species on the two first axes of the

771 FCA. The percentage of species in each cluster is indicated in brackets. B. Ordination of the

772 functional trait modalities on the two first axes of the FCA. C. Distribution of the ants from the six

773 clusters defined in Fig. 6A among the rainforest strata based on their occurrence in samples. 